\title{
Comprehensive Evaluation on Environmental Impact of Green Buildings Considering Sustainable Development
}

\author{
Siyuan Wang ${ }^{1 *}$, Wei Wei ${ }^{2}$ \\ ${ }^{1}$ Department of Engineering Management, Auhui Audit College, Hefei 230000, China \\ ${ }^{2}$ Engineering Technology Department, Anhui Haohui Electric Power Co. Ltd, Hefei 230000, China
}

Corresponding Author Email: syvvong@163.com

https://doi.org/10.18280/ijdne.150319

Received: 9 January 2020

Accepted: 16 April 2020

\section{Keywords:}

green buildings, sustainable development, environmental benefit, building energy consumption, carbon emissions

\begin{abstract}
Featuring energy efficiency, comfort, and economical efficiency, green buildings facilitate resource conservation, environment protection, and sustainable development in China, a country that is rapidly urbanized. However, there is not yet an effective means to quantify the environmental impact of green buildings. Based on environmental sustainability, this paper puts forward a novel method that comprehensively evaluates the environmental impact of green buildings, which includes environmental benefits into post-evaluation. Taking seven green buildings as examples, the indoor environment improvement was measured by temperature, humidity, $\mathrm{CO}_{2}$ content, and illuminance. Besides, the energy consumptions and carbon emissions of green buildings were quantified. The results show that the environmental benefits of green buildings are implicit, including energy-saving benefit, land-saving benefit, water-saving benefit, material-saving benefit, and indoor environment improvement. The seven green buildings were found to meet relevant standards on heating energy consumptions, and have a clear edge in renewable energy consumption. the energy consumptions and indoor environment scores of green buildings are positively correlated. In other words, for a green building, the higher the environmental benefits, the better the comprehensive evaluation result. The research results lay a theoretical basis for quantifying the environmental impact of green buildings.
\end{abstract}

\section{INTRODUCTION}

The rapid economic growth has fuelled the desire for material well-being, resulting in the overdevelopment of the building industry. Currently, the building industry has consumed a growing portion of energies and resources that are utilized in China. The heavy consumption wastes lots of resources and pollutes the environment [1]. Green buildings provide an effective solution to this problem. Besides improving living environment and livelihood, green buildings pave the way towards ecological civilization and sustainable development [2, 3].

Green buildings are still in their infancy in China. Most of them are civil buildings and public buildings. Unlike those in developed countries in Europe and North America, green buildings in China are evolving from single buildings to an entire ecological city [4]. In developed countries, the green building evaluation system focuses on the integration between post-evaluation and environmental benefits, and covers building construction, material performance, work and living environment, and natural environment. Apart from these indices, incremental benefits are included in China's green building evaluation system, that is, environmental and economic benefits are integrated into green buildings [5].

It is of great practical significance to evaluate the environmental benefits of green buildings in the whole lifecycle. Despite the inevitable growth in incremental cost, the development of green buildings benefits the environment and sustainable development in the long run. It is necessary to promote green building evaluation system from the perspective of whole lifecycle [6]. On the macroscale, green buildings develop in sync with social economy, and relate to the progress of our views on life and consumption. More importantly, green buildings are correlated with social harmony and stability, and facilitate resource conservation and environment protection [7].

For the sustainability of building environment, it is important to introduce environmental benefits into the postevaluation of green buildings. However, the existing green building evaluation systems emphasize economic benefits over environmental benefits $[8,9]$. The few systems that consider environmental benefits only focus on a single factor. In the real world, however, environmental benefits are affected by various factors. To fully evaluate environmental benefits, these factors should be weighted according to relative importance. Based on environmental sustainability, this paper puts forward a novel method that comprehensively evaluates the environmental impact of green buildings, which includes environmental benefits into post-evaluation.

\section{METHODOLOGY}

At present, the construction of green buildings is not mandatory but a market behavior. Green buildings refer to the buildings that save resources as much as possible, protect 
environment, and reduce pollution, and coexist harmoniously with the nature throughout the lifecycle [10]. As shown in Figure 1, the number of green building projects in China increased yearly from 2011 to 2018 .

Green buildings have both explicit benefits and implicit benefits. Explicit benefits refer to the most direct economic benefits, while implicit benefits stand for environmental benefits and social benefits. The environmental benefits of green buildings need to be obtained through post-evaluation [11].

The externality coefficients of building-related parameters are important to the quantification of environmental benefits. At present, these coefficients can be measured by market transaction price method, opportunity cost method, recovery and protection cost method, and shadow engineering method [12]. The existing data show that, in the whole lifecycle, the energy consumption in operation and maintenance phases far exceeds that in design and construction phases. The construction of green buildings directly bears on the environmental benefits on the later stage.

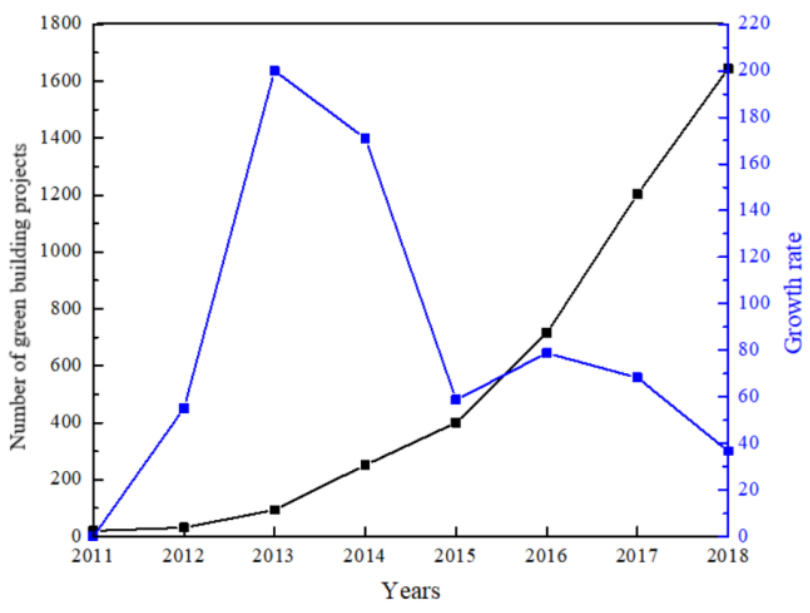

Figure 1. The green building projects in China from 2011 to 2018

\section{RESULTS}

\subsection{Environmental benefits of green buildings}

As shown in Figure 2, the environmental benefits of green buildings include energy-saving benefit, land-saving benefit, water-saving benefit, material-saving benefit, and indoor environment improvement.

To improve building comfort and weaken negative environmental impacts, green buildings are required to make full use of industrial waste, save land resources, rationally adopt green materials, thereby improving the air, thermal, light and acoustic environments $[13,14]$.

Table 1 lists the carbon emission factors of main building materials. It can be seen that steel is the highest carbon emitter, followed in turn by cement, building glass, and cement block.
Each unit of cement block can emit $0.22 \mathrm{t} / \mathrm{m}^{3}$ of carbon dioxide.

The environmental benefits of green buildings are the environmental consequences of our use of these buildings. Throughout its lifecycle, the carbon emissions $E_{t}$ of a green building can be computed by:

$$
\mathrm{E}_{\mathrm{t}}=\mathrm{E}_{\mathrm{m}}+\mathrm{E}_{\mathrm{c}}+\mathrm{E}_{\mathrm{r}}+\mathrm{E}_{\mathrm{td}}-\mathrm{E}_{\mathrm{br}}-\mathrm{E}_{\mathrm{bcs}}
$$

where, $E_{\mathrm{m}}, \mathrm{E}_{\mathrm{c}}, \mathrm{E}_{\mathrm{r}}$ and $\mathrm{E}_{\mathrm{td}}$ are the total carbon emissions of the building in the phases of material production, construction, operation and maintenance, and demolition, respectively; $\mathrm{E}_{\mathrm{br}}$ is the total carbon emissions of the building in the phase of recycling; $\mathrm{E}_{\mathrm{bcs}}$ is the total carbon emissions absorbed and stored by the building in the whole lifecycle.

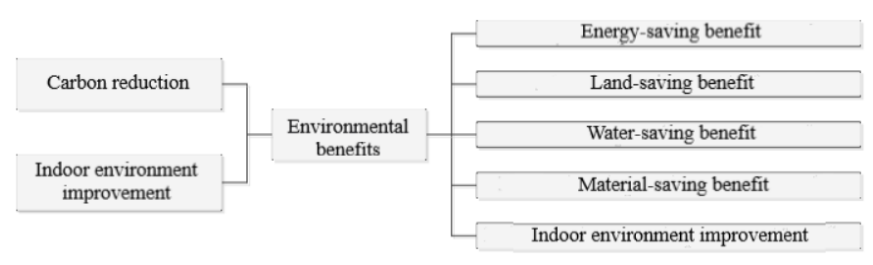

Figure 2. Breakdown of environmental benefits of green buildings

Table 1. Carbon emission factors of main building materials

\begin{tabular}{cc}
\hline Main building materials & Carbon emission factors \\
\hline Cement & $1.35 \mathrm{t} / \mathrm{t}$ \\
Steel & $2.13 \mathrm{t} / \mathrm{t}$ \\
Building glass & $0.96 \mathrm{t} / \mathrm{t}$ \\
Concrete block & $0.22 \mathrm{t} / \mathrm{m}^{3}$ \\
\hline
\end{tabular}

\subsection{Indoor environment improvement}

As shown in Figure 2, the environmental benefits of green buildings fall into two broad categories: carbon reduction, and indoor environment improvement. The latter of a green building is mainly evaluated subjectively.

The physical indoor environment was measured by multiple parameters, including temperature, humidity, air quality, and $\mathrm{CO}_{2}$ content. The lower and upper bounds of each parameter were configured. If these parameters fall between the corresponding bounds, the indoor environment will be comfortable.

To weight these parameters, the relative importance of each parameter was obtained through questionnaire survey. As shown in Table 2, a judgement matrix was set up, subjected to consistency check, and used for weight calculation. Table 3 lists the random consistency index (RI) of each parameter. It can be seen that the consistency index (CI) of our questionnaire was $0.0045<0.1$, that is, our questionnaire is sufficiently consistent.

The intervals and scores of the parameters are given in Table 4, where $\mathrm{C}$ is the satisfaction of experts. The $\mathrm{C}$ values serve as the scoring standard. Based on $\mathrm{C}$ values, it is possible to obtain the mean satisfaction of each parameter.

Table 2. Relative importance of each parameter

\begin{tabular}{ccccc}
\hline & Temperature & Humidity & $\mathbf{C O}_{2}$ content & Illuminance \\
\hline Temperature & 1 & 1.57 & 1.80 & 0.93 \\
Humidity & 0.64 & 1 & 1.03 & 0.80 \\
$\mathrm{CO}_{2}$ content & 0.56 & 0.97 & 1 & 0.62 \\
Illuminance & 1.08 & 1.25 & 1.61 & 1 \\
\hline
\end{tabular}


Table 3. The RIs of each parameter

\begin{tabular}{cccccccccc}
\hline Order & 1 & 2 & 3 & 4 & 5 & 6 & 7 & 8 & 9 \\
\hline RI & 0 & 0.2 & 0.6 & 0.9 & 1.1 & 1.3 & 1.35 & 1.4 & 1.45 \\
\hline
\end{tabular}

Table 4. Intervals and scores of the parameters

\begin{tabular}{cc}
\hline Intervals & Scores \\
\hline $0 \leq \mathrm{C}<0.15$ & 1 \\
$0.15 \leq \mathrm{C}<0.3$ & 2 \\
$0.3 \leq \mathrm{C}<0.45$ & 3 \\
$0.45 \leq \mathrm{C}<0.7$ & 4 \\
$0.7 \leq \mathrm{C}<1$ & 5
\end{tabular}

\section{DISCUSSION}

\subsection{Example analysis}

Considering environmental sustainability, energy consumption and carbon emissions are part of the environmental benefits of buildings. In the post-evaluation of green buildings, the indoor environmental improvement

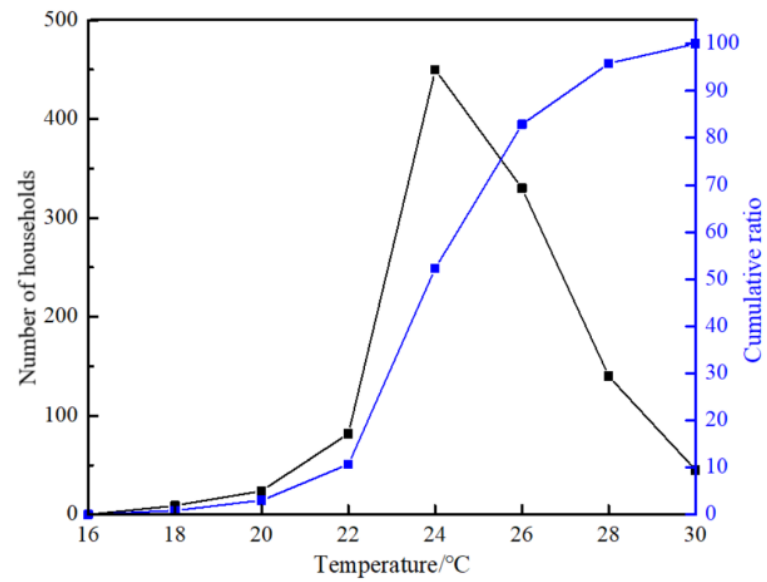

(a) Temperature distribution

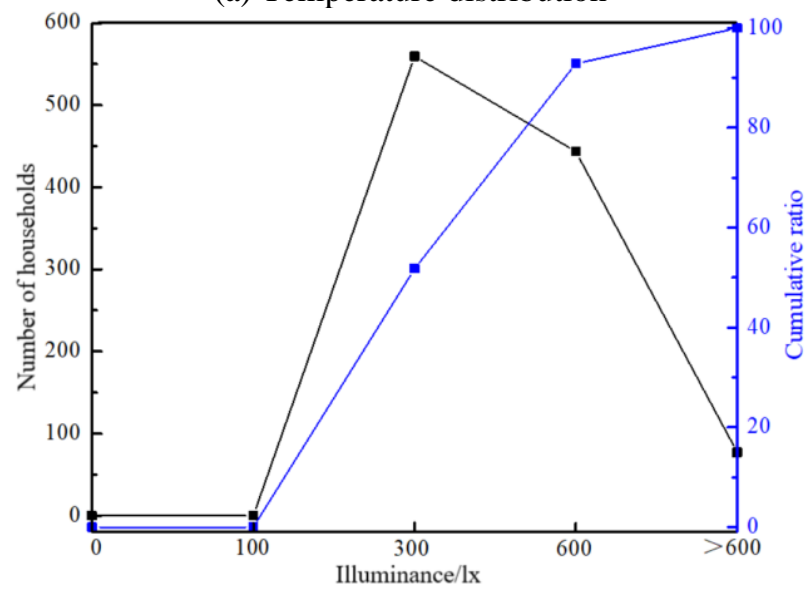

(c) Illuminance distribution directly affects the subjective evaluation of green buildings $[15,16]$.

Seven green buildings were selected from Shibei District, Qingdao, eastern China's Shandong Province for analysis on indoor environmental improvement. The indoor environment was evaluated by four parameters: temperature, humidity, illuminance and $\mathrm{CO}_{2}$ content. Temperature and humidity were captured by an automatic temperature and humidity recorder, the illuminance was measured by an illuminance meter, and $\mathrm{CO}_{2}$ content was obtained with a handheld $\mathrm{CO} 2$ recorder.

Figure 3 shows the mean distribution of indoor environmental parameters of the green buildings in winter. As shown in Figure 3(a), 82\% of the green buildings meet the range of comfortable temperature in winter $\left(18^{\circ} \mathrm{C}-26^{\circ} \mathrm{C}\right)$, while $18 \%$ of them surpassed that range. That is, some green buildings are overheated in winter. As shown in Figure 3(b), only $6.21 \%$ of the green buildings meet the range of comfortable humidity in winter $(30 \%-60 \%)$. As shown in Figure 3(c), $92.86 \%$ of the green buildings meet the range of comfortable illuminance (1001x-4001x). As shown in Figure $3(\mathrm{~d}), 100 \%$ of the green buildings meet the range of comfortable $\mathrm{CO}_{2}$ content $(<1,000 \mathrm{ppm})$. The range of comfortable $\mathrm{CO}_{2}$ content was extracted from The Assessment Standard for Green Buildings (GB/T 50378-2014).

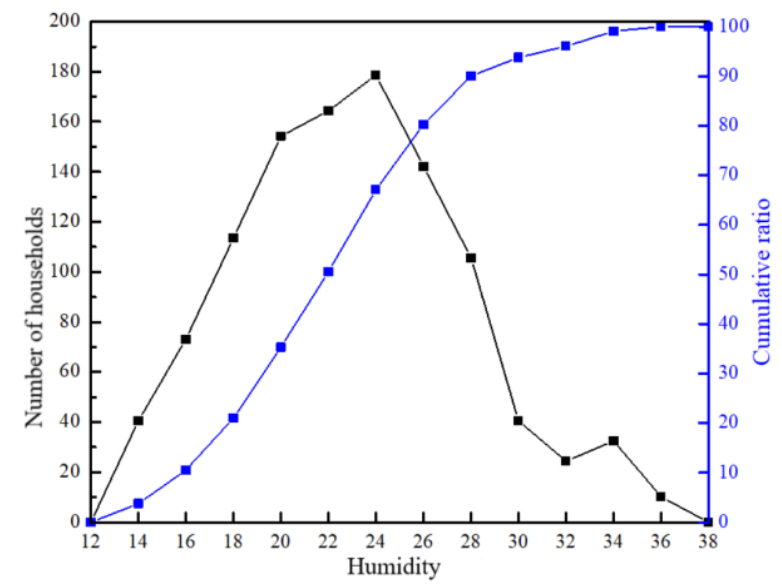

(b) Humidity distribution

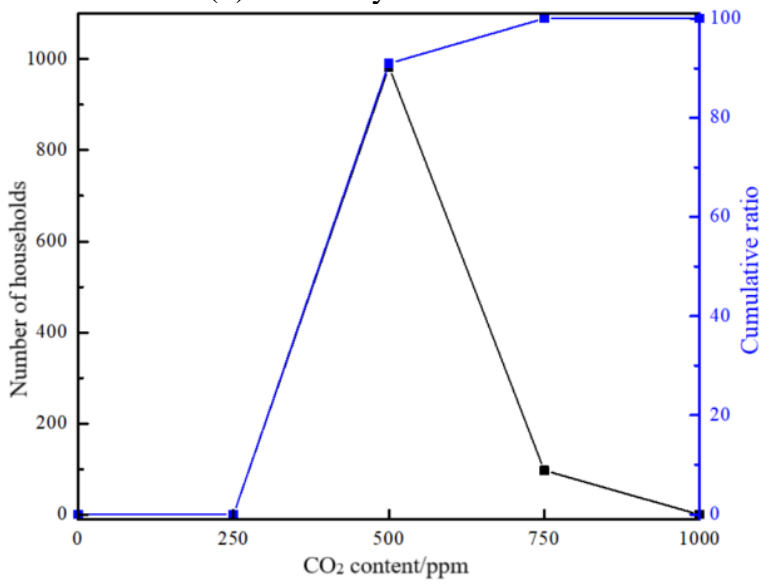

(d) $\mathrm{CO}_{2}$ content distribution

Figure 3. Distribution of indoor environment parameters in winter

\subsection{Statistics on energy consumption}

The energy consumption is an important indicator of the environmental impact of green buildings. It could be quantified by terminal heat method, primary energy conversion algorithm, and equivalent electric conversion algorithm [17, 18].

This paper calculates the consumption of each kind of energy with the equivalent electric conversion algorithm [1921]. The annual mean energy consumptions per unit area of 
the seven public green buildings were tracked and recorded (Figure 4). Obviously, the seven green buildings differed in annual mean energy consumption per unit area. The highest power consumption is conventional system power consumption, followed in turn by heating energy consumption, and renewable energy consumption. The seven green buildings were found to meet relevant standards on heating energy consumptions, and have a clear edge in renewable energy consumption.

Then, the carbon emissions from building energy consumption were computed by formula (1). Since all target buildings are green, no carbon is emitted in the operation and maintenance phases. Hence, the total carbon emissions in these phases, and the total carbon emissions absorbed and stored by the building in the whole lifecycle, were both neglected. As shown in Table 5, the total carbon emissions of the seven green buildings were $4.25 \mathrm{t}$, far smaller than those of the other buildings being investigated.

Figures 5 and 6 are the carbon emission distributions of public buildings and civil buildings, respectively. It can be seen that the carbon emissions of public buildings mainly come from unconventional power consumption, summer cooling, and solar photothermal system. By contrast, the carbon emissions of civil buildings mostly come from indoor power consumption, followed by supply heating consumption and indoor gas consumption.

Figure 7 compares the energy consumptions and indoor environment scores of green buildings with those of ordinary buildings. Based on the indoor environment improvement, the energy consumptions and indoor environment scores of green buildings were found to be positively correlated. In other words, for a green building, the higher the environmental benefits, the better the comprehensive evaluation result.

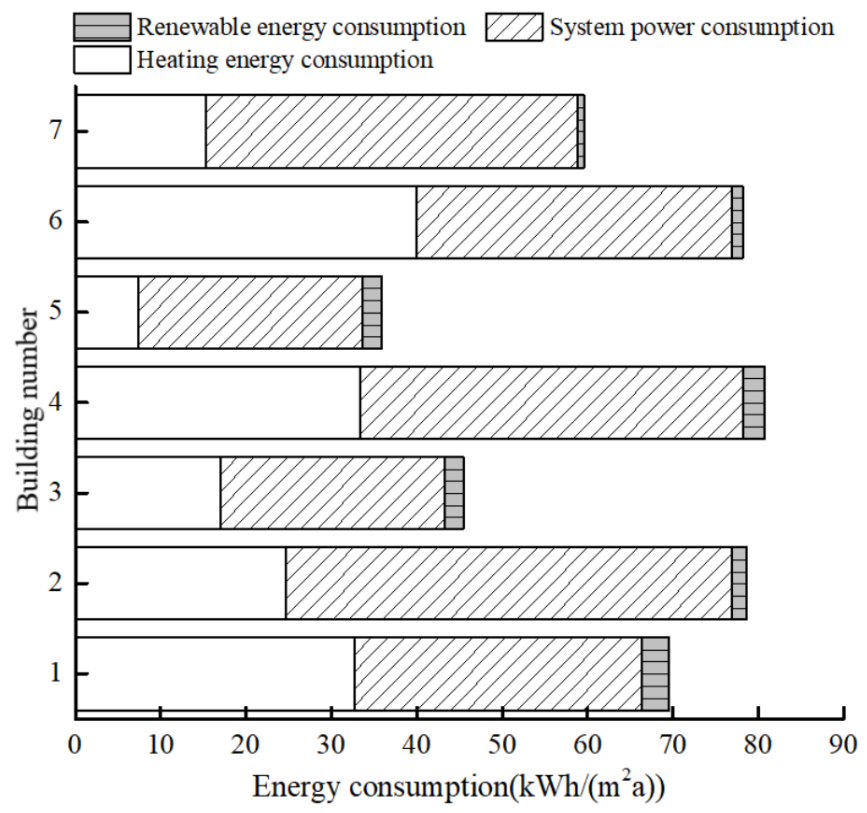

Figure 4. Mean annual energy consumption per unit area of each public green building

Table 5. Carbon emissions from building energy consumption

\begin{tabular}{|c|c|c|c|}
\hline Energy types & Electric energy & Photovoltaic power generation & Solar photothermal system \\
\hline Consumption/kWh & 5309 & 187 & 1715 \\
\hline Carbon emissions/t & 6.57 & 2.32 & 2.09 \\
\hline Total $/ \mathrm{t}$ & & 4.25 & 2.09 \\
\hline Area index $/ \mathrm{t} /\left(\mathrm{m}^{2} \cdot \mathrm{a}\right)$ & & 0.458 & 0.153 \\
\hline
\end{tabular}

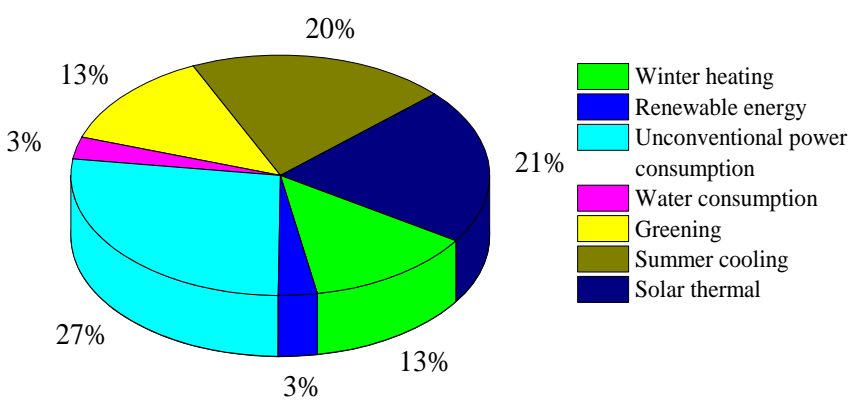

Figure 5. Carbon emission distribution of public buildings

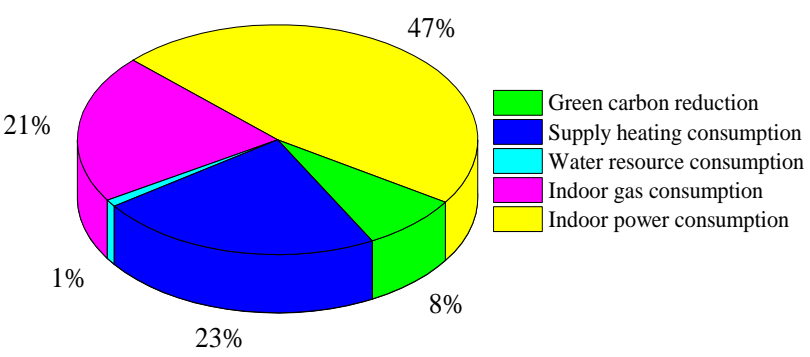

Figure 6. Carbon emission distribution of civil buildings

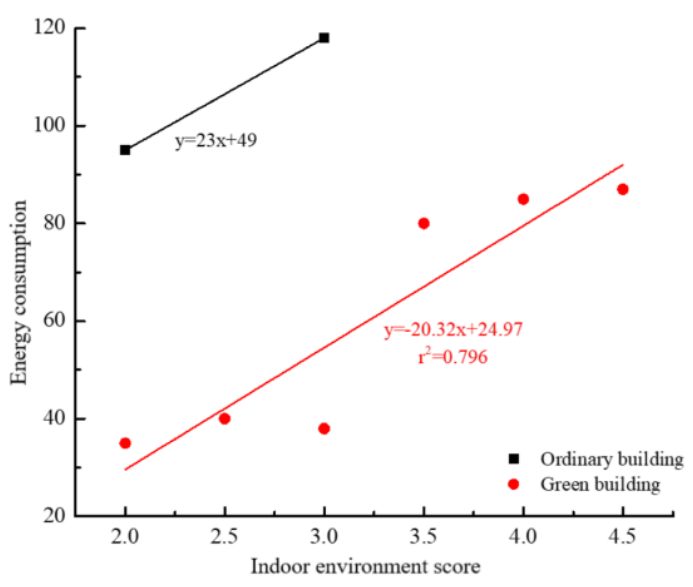

Figure 7. Energy consumptions and indoor environmental scores of green buildings and ordinary buildings

\section{CONCLUSIONS}

In pursuit of environmental sustainability, this paper introduces environmental benefits of green building into postevaluation, creating an effective method to evaluate the environmental benefits of green buildings. The main conclusions are as follows: 
(1) The environmental benefits of green buildings include energy-saving benefit, land-saving benefit, water-saving benefit, material-saving benefit, and indoor environment improvement, which fall into two broad categories: carbon reduction, and indoor environment improvement.

(2) The indoor environment of seven green buildings was evaluated by four parameters: temperature, humidity, illuminance and $\mathrm{CO}_{2}$ content. The evaluation shows that $82 \%$ of the green buildings meet the range of comfortable temperature in winter, while $18 \%$ of them surpassed that range. Only $6.21 \%$ of the green buildings meet the range of comfortable humidity in winter. $92.86 \%$ of the green buildings meet the range of comfortable illuminance. $100 \%$ of the green buildings meet the range of comfortable $\mathrm{CO}_{2}$ content.

(3) The evaluation of indoor environment improvement shows that the energy consumptions and indoor environment scores of green buildings are positively correlated. In other words, for a green building, the higher the environmental benefits, the better the comprehensive evaluation result. The seven green buildings were found to meet relevant standards on heating energy consumptions, and have a clear edge in renewable energy consumption.

\section{REFERENCES}

[1] Trowbridge, M.J., Worden, K., Pyke, C. (2016). Using green building as a model for making health promotion standard in the built environment. Health Affairs, 35(11): 2062-2067. https://doi.org/10.1377/hlthaff.2016.1020

[2] Yu, L., Wang, H., Wang, X., Feng, G. (2017). Study on the measurement of indoor environment quality and enclosure structure thermal defects of green residential buildings in severe cold areas. Procedia Engineering, 205: 3373-3380.

https://doi.org/10.1016/j.proeng.2017.09.844

[3] Gou, Z., Lau, S.S.Y. (2013). Post-occupancy evaluation of the thermal environment in a green building. Facilities, 31(7/8):

357-371. https://doi.org/10.1108/02632771311317493

[4] Hossain, M.F. (2017). Green science: independent building technology to mitigate energy, environment, and climate change. Renewable and Sustainable Energy Reviews, 73:

695-705 https://doi.org/10.1016/j.rser.2017.01.136

[5] Shin, J.H., Miller, S. (2014). Audio-visual environment and the religious experiences in green church buildings: a cross-case study. Journal of Interior Design, 39(3): 124. https://doi.org/10.1111/joid.12030

[6] Pei, Z., Lin, B., Liu, Y., Zhu, Y. (2015). Comparative study on the indoor environment quality of green office buildings in china with a long-term field measurement and investigation. Building and Environment, 84: 80-88. https://doi.org/10.1016/j.buildenv.2014.10.015

[7] Xu, J., Wang, Y., Tao, Z. (2013). Rough approximation based strategy model between a green building developer and a contractor under a fuzzy environment. KnowledgeBased Systems, 46: 54-68. https://doi.org/10.1016/j.knosys.2013.03.002

[8] Cidell, J. (2009). A political ecology of the built environment: LEED certification for green buildings. Local Environment, 14(7): 621-633. https://doi.org/10.1080/13549830903089275

[9] Kohler, N. (2017). From the design of green buildings to resilience management of building stocks. Building Research \& Information, 46(5): 578-593. https://doi.org/10.1080/09613218.2017.1356122

[10] Hou, W.S., Chuang, T.F., Hsieh, E.C., Chang, Y.H. (2012). An analysis of heat insulation efficiency of building outer skins used for green building. Building Services Engineering Research and Technology, 33(4): 407-422. https://doi.org/10.1177/0143624411418153

[11] Ravindu, S., Rameezdeen, R., Zuo, J., Zhou, Z., Chandratilake, R. (2015). Indoor environment quality of green buildings: Case study of an LEED platinum certified factory in a warm humid tropical climate. Building and Environment, 84: 105-113. https://doi.org/10.1016/j.buildenv.2014.11.001

[12] Lin, B., Liu, Y., Wang, Z., Pei, Z., Davies, M. (2016). Measured energy use and indoor environment quality in green office buildings in china. Energy and Buildings, 129: 9-18. https://doi.org/10.1016/j.enbuild.2016.07.057

[13] Lamble, S.P., Corsi, R.L., Morrison, G.C. (2011). Ozone deposition velocities, reaction probabilities and product yields for green building materials. Atmospheric Environment, 45(38): 6965-6972. https://doi.org/10.1016/j.atmosenv.2011.09.025

[14] Raouf, A.M.I., Al-Ghamdi, S.G. (2019). Building information modelling and green buildings: challenges and opportunities. Architectural Engineering \& Design Management, $\quad 15(1-2)$ : 1-28. https://doi.org/10.1080/17452007.2018.1502655

[15] Attaran, S., Celik, B.G. (2020). Students' environmental responsibility and their willingness to pay for green buildings. International Journal of Sustainability in Higher Education, 16(3): 327-340. https://doi.org/10.1108/IJSHE-04-2013-0029

[16] Ziogou, I., Michopoulos, A., Voulgari, V., Zachariadis, T. (2017). Energy, environmental and economic assessment of electricity savings from the operation of green roofs in urban office buildings of a warm Mediterranean region. Journal of Cleaner Production, 168: 346-356. https://doi.org/10.1016/j.jclepro.2017.08.217

[17] Crafford, P.L., Blumentritt, M., Wessels, C.B. (2017). The potential of South African timber products to reduce the environmental impact of buildings. South African Journal of Science, 113(9-10): 56-63. https://doi.org/10.17159/sajs.2017/20160354

[18] Hossain, K.A., Gencturk, B. (2014). Life-cycle environmental impact assessment of reinforced concrete buildings subjected to natural hazards. Journal of Architectural Engineering, A4014001. https://doi.org/10.1061/(ASCE)AE.1943-5568.0000153

[19] Lee, N., Tae, S., Gong, Y., Roh, S. (2017). Integrated building life-cycle assessment model to support south Korea's green building certification system (g-seed). Renewable \& Sustainable Energy Reviews, 76: 43-50. https://doi.org/10.1016/j.rser.2017.03.038

[20] Hossain, M.F. (2018). Green science: Advanced building design technology to mitigate energy and environment. Renewable \& Sustainable Energy Reviews, 81: 30513060. https://doi.org/10.1016/j.rser.2017.08.064

[21] Gou, Z., Lau, S.Y. (2013). Post-occupancy evaluation of the thermal environment in a green building. Facilities, 31(7-8): https://doi.org/10.1108/02632771311317493
357-371. 